\title{
Assessment of Work Related Musculoskeletal Disorders among House Maids of Kolkata, India
}

\author{
Piyali Mukherjee ${ }^{1}$, Anindita Singha Roy ${ }^{2}$, Amit Bandyopadhyay ${ }^{2}$, Somnath Gangopadhyay ${ }^{1, *}$
}

\section{Piyali Mukherjee', Anindita Singha Roy ${ }^{2}$, Amit Bandyopadhyay², Somnath Gangopadhyay ${ }^{1, *}$}

'Occupational Ergonomics Laboratory, Department of Physiology, University of Calcutta, University Colleges of Science and Technology, Kolkata, INDIA. ${ }^{2}$ Sports and Exercise Physiology Laboratory, Department of Physiology, University of Calcutta

University Colleges of Science and Technology, Kolkata, INDIA.

\section{${ }^{*}$ Correspondence}

\section{Dr. Somnath Gangopadhyay} Professor, Occupational Ergonomics Laboratory, Department of Physiology, University of Calcutta, University Colleges of Science and Technology, 92 A. P. C. Road, Kolkata : 700009, INDIA.

Phone: +91 3323508386 (Extn 228)

Email: ganguly1961@gmail.com History

- Submission Date: 24-03-2020;

- Review completed: 15-05-2020;

- Accepted Date: 29-05-2020.

DOI : 10.5530/ijcep.2020.7.2.20

Article Available online http://www.ijcep.org

\section{Copyright}

(C) 2020 Phcog.Net. This is an openaccess article distributed under the terms of the Creative Commons Attribution 4.0 International license.

\begin{abstract}
Background and Aim: Work related musculoskeletal disorders (WMSDs) are common problems among the workers engaged in unorganised sector. Working as a house maid is a very old profession. The objective of the present study was to evaluate the prevalence of WMSDs in house maids of Kolkata. Methods: Ninety-four house maids (age range of 20-60 years) engaged in different household works for minimum 3 years of duration were recruited in this study by random sampling method from different parts of Kolkata, India. They were divided into four groups based on their age and years of working. Physical parameters, assessment of musculoskeletal disorders and analysis of posture were done by using standard methods and procedures. Results: The study revealed different grades of pain in different parts of the body, maximum being the prevalence of low back pain. The intensity and localisation of pain varied in different age groups showing significant relationship with working experiences and daily working hours. Body part wise pain varied during work, rest and sleep times. Conclusion: WMSDs and pain experienced by the house maids were due to their constrained and awkward working postures for longer duration which need to be corrected with immediate interventions.

Key words: Work related musculoskeletal disorders, House maid, Unorganised sector, Low back pain, Posture analysis.
\end{abstract}

\section{INTRODUCTION}

A large number of people are associated with different types of jobs in the informal or unorganised sectors in developing countries. The common characteristics shared by the workers of the informal sectors are intense human labour, prolonged working hours, no work - no pay system, irregular work schedule and lack of additional allowances, resulting in suffering from musculoskeletal disorders (MSDs) which not only deteriorates their physical condition but also augment their mental distress. ${ }^{[1]}$

Almost $60 \%$ of the working population in developing countries are engaged in jobs at unorganised or informal sectors mainly because of the frequently changing economic scenario and ample availability of low cost workers. ${ }^{[1]}$ Work related musculoskeletal disorders (WMSDs) are very common among the informal sector workers in India. Both psychological and physiological risk factors affect WMSDs resulting in discomfort and pain. ${ }^{[2]}$ Most of these problems are generated due to repeated stress, economic hazards and infrastructural insufficiency out of manual material handling $(\mathrm{MMH})$ which causes injuries, pain, suffering, disability, fatalities as well as loss in efficiency and production for workers and their families with concomitant societal economic losses. ${ }^{[3-5]}$ Ciriello et al. ${ }^{[6]}$ identified $\mathrm{MMH}$ as the most frequent and expensive etiology of WMSDs in informal sector

Cite this article: Mukherjee P, Roy AS, Bandyopadhyay A, Gangopadhyay S. Assessment of Work Related Musculoskeletal Disorders among House Maids of Kolkata, India. Int J Clin Exp Physiol. 2020;7(2):81-6. 
find out the relationship of working experience with musculoskeletal disorders in different body parts.

Subjects having less than 3 years of working experience in household works were excluded from this study. The age of each participant was calculated from the "Aadhar Card" which is the National Identification issued by the Government of India. They were paid compensation for loss of pay for taking part in the study. Informed consent was obtained from each worker. Ethical approval for this study was obtained from the Human Research Ethics Committee of Department of Physiology, University of Calcutta.

\section{Assessment of Anthropometric Parameters}

The body height and body weight were measured by using the weighing machine fitted with height measuring rod (Avery India Limited, India). The body mass index (BMI) and body surface area (BSA) of the subjects were calculated by using the standard formulae. ${ }^{[9,10]}$ The waist and hip circumferences were measured by following standard guidelines.

\section{Evaluation of WMSDs}

Work related musculoskeletal disorders or WMSDs were evaluated by using the Modified Nordic Questionnaire. ${ }^{[1]]}$ This questionnaire consists of a series of objective questions with multiple choice responses. A face to face interview was thought to be more reliable in obtaining accurate information from the domestic maids as they belonged to a poor educational background. The questions were grouped in three major sections:

- General information of the workers, i.e., their age, years of experience, etc.

- Work organization and working behaviours

- Assessment of stress at work and detailed questions on physical disorders caused by working environment

- Evaluation of region wise pain in different body parts rated by the workers on a 1 to 10 point scale ( 1 implying no pain and 10 implying maximum pain) called body part discomfort scale or VAS rating. ${ }^{[12]}$

\section{Assessment of Working Posture}

Working posture was assessed by the method of Ovako Working posture Assessment System or OWAS. ${ }^{[13]}$

OWAS identifies the most common work postures for the back (4 postures), arms (3 postures) and legs (7 postures) and the weight of the load handled ( 3 categories). Whole body posture is described by these body parts with a four digit-code. These 252 postures have been classified into four action categories indicating needs for ergonomic changes. The observations were made as "snapshots" and sampling has usually been assured with constant time intervals.

\section{Statistical Analysis of Data}

Data were expressed as mean \pm SD. One-way analysis of variance (ANOVA) followed by Bonferroni post hoc analysis was adopted to compute the significance of difference in mean values obtained in different age groups. Chi square test was employed to test the relationship between working experience and pain in different body parts. The level of significance was set at $p<0.05$. The entire statistical analysis was done by using SPSS 16 software.

\section{RESULTS}

Ninety-four house maids were recruited in the study and all of them successfully completed the questionnaire and physical examination methods. The physical parameters, work experience and daily working
Table 1: Physical parameters, work experience and daily working hour of the house maids of different age groups.

\begin{tabular}{|c|c|c|c|c|}
\hline Parameter & $\begin{array}{c}20-30 \text { Years } \\
\quad(n=38)\end{array}$ & $\begin{array}{c}31-40 \text { Years } \\
(n=33)\end{array}$ & $\begin{array}{c}\text { 41-50 Years } \\
\qquad(n=9)\end{array}$ & $\begin{array}{c}51-60 \text { Years } \\
\quad(n=14)\end{array}$ \\
\hline Body weight $(\mathrm{kg})$ & $52.74 \pm 10.17$ & $53.79 \pm 12.47$ & $64.78 \pm 11.10^{*}$ & $56.71 \pm 10.37$ \\
\hline Body height $(\mathrm{cm})$ & $148 \pm 4.82$ & $151.48 \pm 5.55$ & $155.78 \pm 4.46^{*}$ & $150.29 \pm 7.98$ \\
\hline BMI $\left(\mathrm{kg} \cdot \mathrm{m}^{-2}\right)$ & $23.97 \pm 3.94$ & $23.40 \pm 5.11$ & $26.61 \pm 3.98$ & $24.98 \pm 3.28$ \\
\hline $\operatorname{BSA}\left(\mathrm{m}^{2}\right)$ & $1.50 \pm 0.15$ & $1.54 \pm 0.18$ & $1.70 \pm 0.15^{*}$ & $1.57 \pm 0.17$ \\
\hline $\begin{array}{c}\text { Waist } \\
\text { circumference }(\mathrm{cm})\end{array}$ & $75.73 \pm 9.41$ & $79.73 \pm 15.33$ & $89.89 \pm 13.42^{*}$ & $83.64 \pm 12.74$ \\
\hline $\begin{array}{l}\text { Hip circumference } \\
(\mathrm{cm})\end{array}$ & $89.10 \pm 8.44$ & $89.06 \pm 12.15$ & $100.33 \pm 9.66^{*}$ & $90.64 \pm 15.44$ \\
\hline W-H Ratio & $0.85 \pm 0.07$ & $0.89 \pm 0.11$ & $0.89 \pm 0.05$ & $0.93 \pm 0.06^{*}$ \\
\hline $\begin{array}{l}\text { Work Experience } \\
\text { (Yrs) }\end{array}$ & $2.37 \pm 1.44$ & $8.72 \pm 4.26$ & $13.0 \pm 7.95$ & $10.43 \pm 5.64$ \\
\hline $\begin{array}{l}\text { Work Duration } \\
\left(\text { hrs.day }^{-1}\right)\end{array}$ & $4.16 \pm 2.34$ & $5.76 \pm 1.96^{*}$ & $9.22 \pm 2.28^{\star}$ & $5.71 \pm 1.86$ \\
\hline
\end{tabular}

BMI: Body mass index; BSA: Body surface area; W-H ratio: Waist-Hip ratio.

Values are expressed as mean \pm SD; One Way ANOVA showed significant difference $(p<0.05)$, Bonferroni Post-hoc analysis was performed $\left({ }^{*} p<0.05\right)$

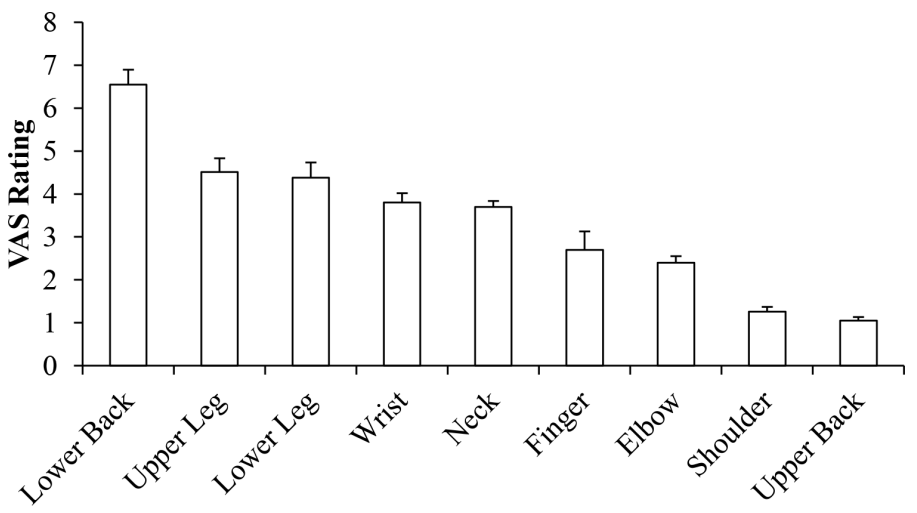

Figure 1: Body parts discomfort (pain) score calculated in terms of VAS Rating in different body parts among house maids of Kolkata.

hour of the subjects have been presented in the Table 1. The body weight, body height, BSA, waist circumference and hip circumference depicted significant difference $(p<0.05)$ in the age group of $41-50$ years whereas 51-60 years of age group showed significant difference in waist-hip ratio (W/H Ratio).

Score of discomfort (pain) in different body parts of the female house maids of Kolkata has been presented in figure 1. Maximum pain was reported in low back followed by upper leg, lower leg, wrist and neck. The relationship between pain intensity in different body parts and years of working experience of the participants has been presented in Table 2 . Chi square statistic depicted significant relationship between working experience and pain intensity in different body parts, except in case of neck and shoulder.

The relationship between pain intensity in different body parts and duration of work per day has been presented in Table 3. Chi square statistic depicted significant relationship of pain intensities in different body parts with the duration of daily working hours, except in case of neck and shoulder. Percentage of respondents according to their discomfort (pain) in different body parts at different times is shown in Figure 2 and 3. 
Table 2: Relationship of years of working experience with pain intensity in different body parts of the house maids.

\begin{tabular}{|c|c|c|c|c|c|c|c|c|}
\hline & & $\begin{array}{c}1-5 \\
\text { Years } \\
(n=46)\end{array}$ & $\begin{array}{c}6-10 \\
\text { Years } \\
(n=28)\end{array}$ & $\begin{array}{l}11-15 \\
\text { Years } \\
(n=8)\end{array}$ & $\begin{array}{l}16-20 \\
\text { Years } \\
(n=8)\end{array}$ & $\begin{array}{l}21-26 \\
\text { Years } \\
(n=4)\end{array}$ & $\begin{array}{c}\text { Chi } \\
\text { Square }\end{array}$ & $P$ value \\
\hline \multirow[t]{2}{*}{ Neck } & Yes & 28 & 22 & 8 & 8 & 2 & 2.68 & $0.61 \mathrm{NS}$ \\
\hline & No & 18 & 6 & 0 & 0 & 2 & & \\
\hline \multirow[t]{2}{*}{ Shoulder } & Yes & 4 & 18 & 4 & 4 & 2 & 5.91 & $0.20 \mathrm{NS}$ \\
\hline & No & 42 & 10 & 4 & 4 & 2 & & \\
\hline \multirow[t]{2}{*}{ Upper back } & Yes & 8 & 12 & 4 & 2 & 2 & 11.21 & 0.03 \\
\hline & No & 38 & 16 & 4 & 6 & 2 & & \\
\hline \multirow[t]{2}{*}{ Lower back } & Yes & 40 & 26 & 6 & 6 & 4 & 9.78 & 0.04 \\
\hline & No & 6 & 02 & 2 & 2 & 0 & & \\
\hline \multirow[t]{2}{*}{ Elbow } & Yes & 23 & 16 & 4 & 4 & 4 & 12.63 & 0.01 \\
\hline & No & 23 & 12 & 4 & 4 & 0 & & \\
\hline \multirow[t]{2}{*}{ Finger } & Yes & 22 & 14 & 4 & 4 & 4 & 26.90 & 0.001 \\
\hline & No & 24 & 14 & 4 & 4 & 0 & & \\
\hline \multirow[t]{2}{*}{ Wrist } & Yes & 26 & 20 & 4 & 4 & 4 & 9.80 & 0.04 \\
\hline & No & 20 & 8 & 4 & 4 & 0 & & \\
\hline \multirow[t]{2}{*}{ Upper leg } & Yes & 29 & 20 & 6 & 2 & 4 & 12.06 & 0.01 \\
\hline & No & 17 & 8 & 2 & 6 & 0 & & \\
\hline \multirow[t]{2}{*}{ Lower leg } & Yes & 30 & 22 & 6 & 2 & 2 & 13.47 & 0.01 \\
\hline & No & 16 & 6 & 2 & 6 & 2 & & \\
\hline
\end{tabular}

NS $=$ Not significant

Table 3: Relationship of duration of work per day with pain intensity in different body parts of the house maids.

\begin{tabular}{|c|c|c|c|c|c|c|}
\hline & & $1-4 \mathrm{hr}$ & $5-8 \mathrm{hr}$ & $9-12 \mathrm{hr}$ & Chi Square & $P$ value \\
\hline \multirow[t]{2}{*}{ Neck } & Yes & 22 & 37 & 10 & 5.63 & $0.06 \mathrm{NS}$ \\
\hline & No & 8 & 13 & 4 & & \\
\hline \multirow[t]{2}{*}{ Shoulder } & Yes & 10 & 15 & 8 & 4.13 & $0.13 \mathrm{NS}$ \\
\hline & No & 20 & 35 & 6 & & \\
\hline \multirow[t]{2}{*}{ Upper back } & Yes & 8 & 16 & 6 & 31.04 & 0.001 \\
\hline & No & 22 & 34 & 8 & & \\
\hline \multirow[t]{2}{*}{ Lower back } & Yes & 24 & 44 & 14 & 8.48 & 0.01 \\
\hline & No & 6 & 6 & 0 & & \\
\hline \multirow[t]{2}{*}{ Elbow } & Yes & 12 & 28 & 10 & 41.65 & 0.001 \\
\hline & No & 18 & 22 & 4 & & \\
\hline \multirow[t]{2}{*}{ Finger } & Yes & 8 & 29 & 8 & 8.78 & 0.01 \\
\hline & No & 22 & 21 & 6 & & \\
\hline \multirow[t]{2}{*}{ Wrist } & Yes & 14 & 31 & 10 & 9.41 & 0.009 \\
\hline & No & 16 & 19 & 4 & & \\
\hline \multirow[t]{2}{*}{ Upper leg } & Yes & 14 & 26 & 12 & 10.58 & 0.005 \\
\hline & No & 16 & 14 & 2 & & \\
\hline \multirow[t]{2}{*}{ Lower leg } & Yes & 24 & 25 & 12 & 7.55 & 0.02 \\
\hline & No & 6 & 25 & 2 & & \\
\hline
\end{tabular}

NS = not significant

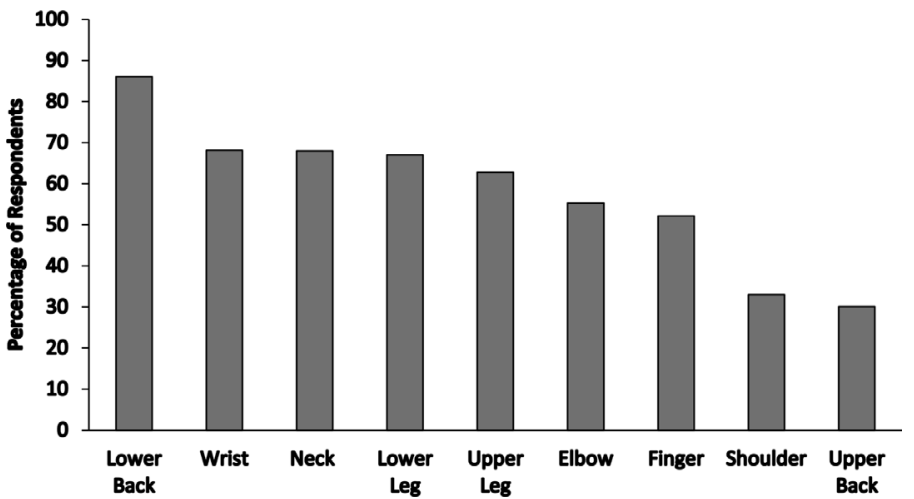

Figure 2: Percentage of respondents on pain in different body parts.

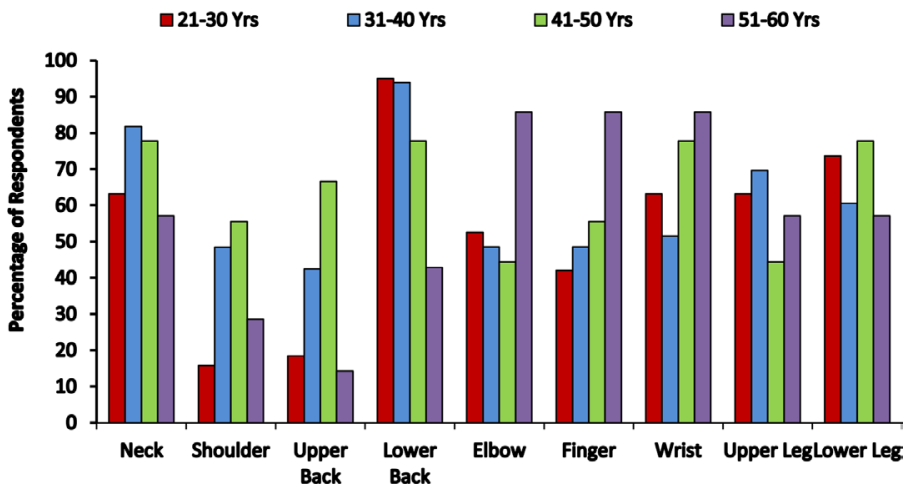

Figure 3: Age group wise percentage of respondents on pain in different body parts.

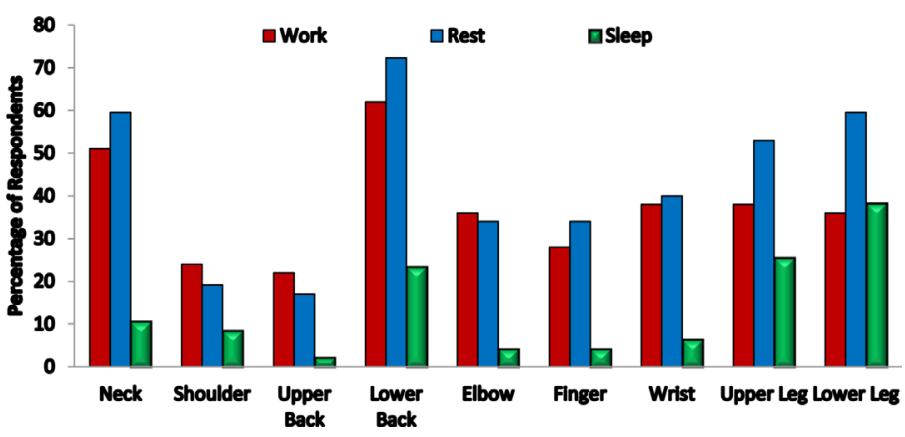

Figure 4: Percentage of respondents according to their pain in different body parts during work, rest and sleep.

Different intensity of discomfort was reported by the participants at different body parts at the time of work, rest and sleep (Figure 4). Maximum discomfort experienced by the respondents during work and rest was in the lower back while pain at the lower leg caused maximum discomfort during sleep. Analysis of working posture by using Ovaku Working Posture Analysis System (OWAS) method has been shown in Table 4. Three postures which were predominantly used by these house maids were considered during working posture analysis.

\section{DISCUSSION}

Several challenges towards health and safety managements have been adopted in the context of Occupational Ergonomics to integrate the concepts of working conditions and working environment into 
Table 4: Analysis of working posture by using OWAS method.

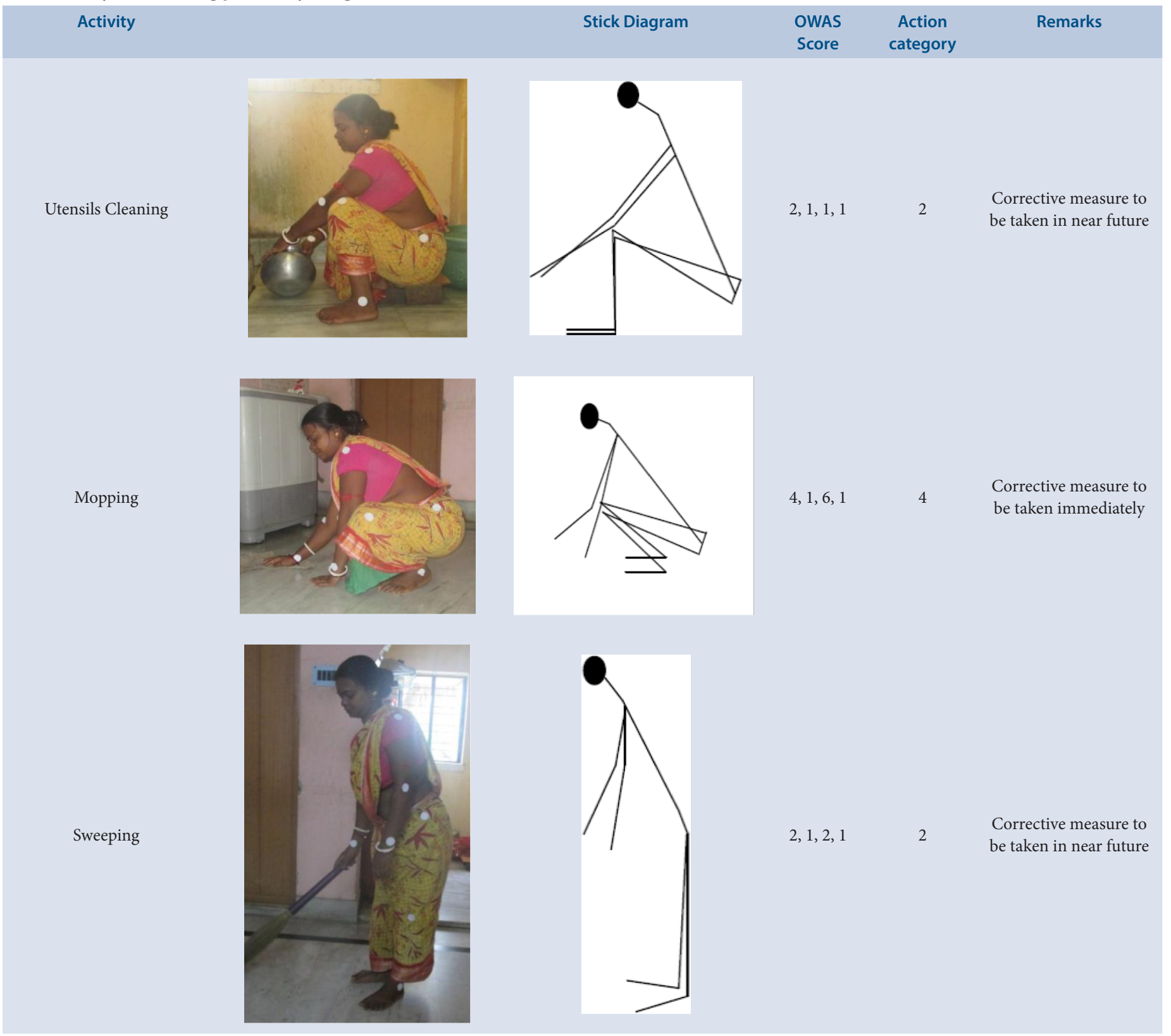

occupational safety and health. Unlike most approaches by psychology and other applied sciences or technologies, ergonomics does not view men and women as variables to be adjusted. Exploring as a "political technology", ergonomics not only examines the work situations in which the workers find themselves comfortable but also promotes working conditions that permit working men and women to engender better productivity. ${ }^{[14]}$ Women's labour participation has been largely focused in agricultural and allied sectors, often erroneously considered to be only form of paid work available to the women of lower strata. In contrast, the house maids were rather neglected in health sector although they contribute a lot in domestic work of their employers. ${ }^{[15]}$

According to ILO, $83 \%$ of domestic workers are women who perform a variety of household services for an individual or a family, from providing care for children and elderly dependents to cleaning and household maintenance, known as housekeeping. Responsibilities may also include cooking, doing laundry and ironing, food shopping and other household errands. Some domestic workers live within the household where they work. This profession provides the livelihood of a large section of women workers engaged in unorganised sectors in West Bengal, India. ${ }^{[16]}$ It is a very old profession that unfortunately did not receive due care in its long run. The condition of the domestic workers is very pity and worsened considerably day by day in respect to the contemporary world. Even they contribute more time to accomplish the household works in their employer's house than they can offer for their own household works.

In spite of their immense role in the management of household works, house maids face various problems in their workplace including psychosocial problems. In today's scenario they have to work in a very small place, especially while cleaning the utensils. Other works also involve abnormal posture that is extremely stressful for them. Therefore, occasionally they report musculoskeletal disorders which often become 
a major cause of their absenteeism. Besides, the wage they get is substantially small and there is no fixed increment for them.

Recruited subjects belonged to the age group of 20-60 years and they were divided into four (4) age groups (Table 1). The sample size in the older age groups (i.e., 41-50 years and 51-60 years) was considerably less than the younger ones because with the progression of age they fail to perform these domestic works due to aging related health problems and thus quit from this profession. However, the coefficients of variation of the studied parameters were considerably small enough to accept this sample size in the concerned age groups as adequate.

One way ANOVA followed by Bonferroni post-hoc analysis depicted that body mass, body height, BSA, waist and hip circumference, waist and hip $(\mathrm{W} / \mathrm{H})$ ratio and work duration were significantly higher in the age group of 41-50 years. Duration of work per day was significantly higher in the 41 to 50 years of age group. This might be due to their better efficiency and skill developed out of working experience of almost twenty years or more. However, daily working hours decreased with further increase in age, i.e., in the 51-60 years of age group probably due to their aging related decline in efficiency and performance ability. Gradual increase in daily working hours from 20 years onwards was might also be due to their intension of earning more wages for better living. Determination of WMSDs by Modified Nordic Questionnaire depicted maximum prevalence of pain in the lower back followed by upper leg, lower leg, wrist and neck (Figure 1). Discomfort felt by the house maids in the other regions of body parts include finger, elbow, upper back and shoulder. It was evident that the house maids were suffering from immense discomfort due to pain in different body parts. This might be attributed to their repetitive movement of body parts during their prolonged work..$^{[12]}$

Percentage of respondents about the pain felt in different body parts has been represented in Figure 2 and Figure 3. The percentage varied when the responses were plotted in the entire population (Figure 2) and in different age groups (Figure 3). Prevalence of lower back pain was higher in the age group of 21-30 years and 31-40 years whereas the pain in the elbow, finger and wrist was maximally prevalent in 51-60 yearrs of age group.

Recruited subjects had different working experiences and attempt was made to evaluate the relationship of years of working experiences with pain felt in different body parts. Chi square analysis depicted significant relationship of years of engagement in this job with the pain felt in different body parts (Table 2). This revealed that intensity of pain in different segments of the body in house maids was influenced by the working experience. So, this is entirely due to the development of work related musculoskeletal disorder. Therefore it may be again postulated that their awkward working postures might be the causative factor for the prevalence of pain in different body segments. This is further supported by the finding that the daily working duration has significant correlation with pain in different body parts. However, neck and shoulder pain did not exhibit any significant correlation neither with working experience nor with duration of work. Younger age groups had considerably high prevalence of pain discomfort in the neck, lower back, elbow, wrist, lower leg and upper leg regions probably because they were the beginners in the profession with least experience among all these age groups. They were still unable to accustom with the working situations (Figure 3).

Percentage of respondents for pain in the neck, shoulder, upper back, lower back, wrist and lower leg was considerably high in the 41-50 years of age group of house maids. This might be not only due to their maximum working experiences but also due to their maximum daily working hours. Moreover, they also had to do the household works in their own family which imposed further burden that might be responsible for causing more WMSDs.

On the other hand, the senior age group (51-60 years) had almost half of the daily working hours than the 41-50 years of age group. Moreover, the 51-60 years of age group of house maids performed their tasks in their employers' house and they reported that after returning home they took rest instead of doing their own household works which in turn were performed by the younger female members (daughter, daughter in law, etc.) of their family. This might be the reason for lower rate of prevalence of pain discomfort in major body parts, e.g., neck, shoulder, lower back, upper leg and lower leg in spite of their higher age. However, existence of higher pain discomfort in the wrist, finger and elbow in the 51-60 years of age group might be attributed to their aging related decline in muscle strength and power.

Attempt was made to evaluate the pain felt by the participants during work, rest and sleep (Figure 4). Maximum percentage of respondents indicated that maximum pain was felt in the lower back during work, rest and sleep. Neck was the next affected region during work and rest while lower leg was the second most pain evoking region during sleeping time. Lower leg and neck produced almost similar intensity of pain during rest among all the subjects. Upper back, elbow, finger and wrist are the regions where minimum discomfort was felt during sleep. Considerably higher intensity of pain was reported in finger, elbow and wrist during rest while lower back and upper leg produced noticeable degree of pain during work. Least pain was reported in upper back, elbow, finger and wrist during sleep. There is a probability of prevalence of Carpal Tunnel Syndrome in the senior age group of house maids.

The results of posture analysis were shown in Table 4 . The posture mostly adopted during their work involves squatting, forward bending in sitting and forward bending in standing. They also use twisting and bending of the body during the work. All these postures require corrective measure need to be taken either immediately or in near future. These awkward postures along with occasional jerking and weight lifting movements may be the attributing factors for the occurrence of WMSDs. Awkward postures are highly associated with WMSDs especially with lower back pain as also evident in the present investigation. ${ }^{[17,18]}$ Spine, especially the vertebral discs is affected by posture, location and weight of a load. ${ }^{[19]}$ Therefore, it may be hypothesised that occurrence of WMSDs in house maids of the present study was due to their awkward postures.

\section{CONCLUSION}

It may be concluded from the study that the house maids of Kolkata, India are suffering from different grades of pain in different joints and parts of the body. The prevalence of pain is maximum at the lower back region. The intensity and localization of pain varied in different age groups and that showed significant relationship not only with the working experience but also with the duration of daily working hours of the house maids. Thus, it is evident that the prevalence of pain in different body segments of the studied population is entirely due to development of WMSDs. Body region wise pain varied during work, rest and sleep. WMSDs observed in different body parts were due to their awkward working postures which need to be corrected with immediate intervention, e.g., proper application of work rest cycle, changing the working posture by modifying the work station and equipment, introduction of proper work place for utensils cleaning and use of developed gadgets for floor mopping.

\section{ACKNOWLEDGEMENT}

Authors are indebted to the subjects recruited in the study for their whole hearted cooperation to complete this investigation. 


\section{CONFLICT OF INTEREST}

The authors declare that they have no conflict of interest.

\section{ABBREVIATIONS}

WMSDs: Work related Musculoskeletal Disorder; MMH: Manual Material Handling; BMI: Body Mass Index; BSA: Body Surface Area; OWAS: Ovako Working posture Assessment System; W-H Ratio: Waist-Hip Ratio (W/H Ratio)

\section{REFERENCES}

1. Gangopadhyay S, Dev S. Design and evaluation of ergonomic interventions for the prevention of musculoskeletal disorders in India. Ann Occup Environ Med. 2014;26(1):18

2. Gangopadhyay S, Dev S, Das T, Ghoshal G, Ara T. An ergonomics study on the prevalence of musculoskeletal disorders among Indian bus conductors. JOSE. 2014;18:521-30

3. Sarkar K, Dev S, Das T, Gangopadhyay S. Prevalence of musculoskeletal disorder among the manual material handling workers of Central Market area Kolkata, India. Int J Curr Res Aca Rev. 2016;4:16-24.

4. Myers D, Silverstein B, Nelson NA. Predictors of shoulder and back injuries in nursing home workers: A prospective study. Am J Ind Med. 2002;41(6):466-76.

5. Marras WS. The future of research in understanding and controlling work related low back disorders. Ergonomics. 2005;48(5):464-77.

6. Ciriello VM, Dempsey PG, Maikala RV, O'Brien NV. Secular changes in psychophysically determined maximum acceptable weights and forces over 20 years for male industrial workers. Ergonomics. 2008;51(5):593-601.

7. Massaccesi M, Pagnotta A, Soccetti A, Masali M, Masiero C, Greco F. Investigation of work related disorders in truck drivers using RULA method. Appl Ergon.
2003;34(4):303-7.

8. Hulshof CTJ, Verbeek JHAM, Braam ITJ, Bovenzi M, Vandijk FJH. Evaluation of an occupational health intervention programme on whole body vibration in fork lift truck drivers: A controlled trial. Occup Environ Med. 2006;63(7):461-8.

9. Cole TJ, Bellizzi MC, Flegal KM, Dietz WH. Establishing a standard definition for child overweight and obesity worldwide: International survey. BMJ. 2000;320(7244):1240-3.

10. Banerjee S, Sen RN. Determination of surface area of body of Indians. J Appl Physiol. 1955:7(6):585-8.

11. Kuorinka I, Jonsson B, Kilbom A, Vinterberg H, Sorensen FB, Anderrson G, et al. Standardised Nordic questionnaires for the analysis of musculoskeletal symptoms. Appl Ergon. 1987;18(13):233-7.

12. Reynolds JL, Drury G, Broderick RL. A field methodology for the control of musculoskeletal injuries. Appl Ergon. 1994;25(1):3-16.

13. Karhu $O$, Kansi $P$, Kuorinka I. Correcting working postures in industry: A practical method for analysis. Appl Ergon. 1977;8(4):199-201.

14. Theureau JP. In: Concevoir pour I'action et al. communication, essais d'ergonomie cognitive. Bern: Peter Lang. 1992;112-7.

15. Kothari U. "Women's Work and Rural Transformation in India". Unpublished Ph.D. Diss., University of Edinburgh, Edinburgh: UK. 1991.

16. Gangopadhyay S, Chakrabarty S, Sarkar K, Dev S, Das T. Evaluation of low back pain among Chikan embroidery workers of West Bengal. J Ind Eng Manag Innov. 2014;1(1):2-12

17. National Institute for Occupational Safety and Health. Epidemiological basis for manual lifting guidelines, by A. Garg, (NIOSH Report). Department of Health and Human Services Cincinnati. 1989

18. Punnett L, Fine LJ, Keyserling WM, Herrin GD, Chaffin DB. Back disorder and non-neutral trunk postures of automobile assembly workers. J Work Environ Health. 1991;17:337-46

19. Mcgill SM, RW Norman. Dynamically and statistically determined low back moments during lifting. J Biomech. 1985:18(12):877-88.

Cite this article: Mukherjee P, Roy AS, Bandyopadhyay A, Gangopadhyay S. Assessment of Work Related Musculoskeletal Disorders among House Maids of Kolkata, India. Int J Clin Exp Physiol. 2020;7(2):81-6. 